\title{
Public Control over the Implementation of the Best Available Technologies as an Important Element of the Country's Modern Environmental Policy
}

\author{
Alexander Zakondyrin ${ }^{1}$ \\ ${ }^{1}$ Association of Developers of Environmental Technologies and Environmental Initiatives, General \\ Director, 115054, 3rd Monetchikovsky per., 11/1, 501, Moscow, Russia
}

\begin{abstract}
The urgent need for the formation of an open and transparent system of public control and environmental and technological assessment of the implementation and application of the best available technologies (BAT) at the largest industrial enterprises of Russia (primarily at enterprises of the Ist Hazard Category) is justified. As an effective measure for forming such a system, the possibility of introducing the national standard "Best Available Technologies. Methodological recommendations for conducting a public expert environmental and technological assessment of the introduction of BAT in enterprises" is described. For consideration and discussion of readers submitted a draft of this document, developed by the author of this article. The basic concept of the proposed document is to establish clear requirements for the procedure and procedure for conducting public audits of BAT implementation. According to the author's idea, the recommended standard will be a comprehensive document aimed at solving a whole range of urgent problems in the field of research. It is expected that its implementation will contribute to enhancing the transparency of financial flows allocated for the implementation of the National Ecological Project, as well as its separate federal project, "Implementation of the Best Available Technologies". A general increase in the quality, efficiency and transparency of the implemented environmental policy in the country is also expected.
\end{abstract}

\section{Introduction}

The priority areas of state policy and strategic planning of the Russian Federation dictate the need to form a high-tech industry in the country, increase its competitiveness, ensure an innovative type of economic development while reducing the negative impact on the environment $[1,2]$. It is supposed to realize the above tasks by creating effective mechanisms for law enforcement in the fields of industry, environmental protection and environmental management, energy conservation and energy efficiency, as well as through the coordinated interaction of its participants in the process of regulating their relations [3-5].

The role and importance of using the best available technologies (BAT) in improving the overall level of economic development of the country, as well as the effectiveness of 
environmental protection around the world, is emphasized not only in the relevant regulatory framework, but also in numerous domestic and foreign literature [6-12].

At the same time, the publications often discuss methods for estimating costs when enterprises switch to BAT, analyze the problems of legal regulation of interesting aspects, features and prospects of using BAT in various regions and sectors of the economy.

As many authors rightly remark, the transition to the principles of the best available technologies (BAT) and the introduction of modern technologies in the industrial sector of the Russian Federation has become one of the tools for the ecological and technological modernization of the economy of the whole country.

However, despite the relevance of the issues raised, as well as the relative elaboration of aspects related to the necessity and importance of introducing BAT in modern industry, the mechanism that would allow for effective and timely public control in this direction has not yet been clearly regulated.

In the framework of this article, the author will try to partially fill the gap, by submitting to the readers a draft of the proposed national standard for implementation. The marked document, according to the author's idea, will include recommendations on conducting a public expert environmental and technological assessment of the introduction of BAT in enterprises that have a negative impact on the environment.

\section{Public control over the introduction of BAT as an element of the country's modern environmental policy: the importance of implementation and key priorities}

In 2017, the first stage of the transition to state regulation based on the BAT was completed: the regulatory legal framework was formed, instructions were given to the federal executive authorities and authorities of the constituent entities of the Russian Federation, 51 information and technical reference books (ITRB) on BAT were developed and approved.

The next stage involves the refinement of the system for issuing, monitoring, monitoring and evaluating the effectiveness of environmental permits (EP), introduction of a set of technical means providing automatic measurements and accounting of indicators of pollutant emissions and (or) discharges of pollutants, fixing and transmitting information on relevant indicators, introduction of new government support measures for business entities, assistance in reducing the share of imported equipment.

The solution of these and many other equally important tasks was established in the federal project "Implementation of the best available technologies" within the framework of the national project "Ecology", in which the transition to BAT is considered as the formation of a competitive industry that ensures the transition of the economy countries from the export of raw materials to an innovative type of development with a simultaneous increase in the efficiency of resource use, and a reduction in negative environmental impacts.

The importance of introducing and actively applying the best available technologies (BAT) is not in doubt, which, as noted earlier, is emphasized not only by the legislator himself, but also by numerous Russian and foreign authors who regularly publish articles on this topic.

It should be noted that for the implementation of the federal project "Implementation of the best available technologies", in which several departments, dozens of public and expert organizations, thousands of enterprises of the most different sectors of the economy take part, financing in the amount of 27.3 billion rubles is planned from the federal budget and 2.4 trillion rubles extrabudgetary funds [10]. For a visual comparison, we note that the planned funds for the implementation of the project are approximately comparable to the average annual budget of the largest city in our country. Therefore, the Law of Moscow 
dated November 21, 2018 No. 30 approved the key characteristics of the capital budget for three years. In accordance with Part 2 of Art. 1 of the specified normative legal act, the total amount of city revenues planned for 2020 should be 2.447 trillion rubles, and estimated expenses - 2.668 trillion rubles respectively [11].

Obviously, at such scales of cash flows, more careful control of the distribution of financial resources, including allocated for the implementation of the federal project under consideration, is necessary. It is advisable to ensure transparency in the targeted use of investment funds. At the same time, the author of this work is convinced that it is public checks of the introduction of BAT at the enterprises that are based on the principles of independence and reasonableness that can significantly increase the overall effectiveness of environmental policies implemented at the present stage in Russia.

The importance of public control in providing strategically important areas of activity of the state, as well as the bodies, institutes, organizations and institutions functioning in it, is also emphasized in numerous works of the scientific plan. Nevertheless, the role of public control in ensuring the quality and effectiveness of the implementation of the federal project "Implementation of the best available technologies" is practically not disclosed.

Based on the foregoing, recognizing the importance and relevance of the areas highlighted here, the author of this article tried to develop and justify a separate national standard, the introduction of which, in his opinion, will contribute to the solution of many pressing problems in the field under study.

\section{The purpose, nature and structure of the developed standard}

The standard under development is intended to establish requirements for the procedure for conducting public expert environmental-technological assessment of BAT implementation at enterprises recognized as objects of negative impact on the environment of Category I. The document is aimed at the implementation of a high-quality and timely independent assessment of the effectiveness of the introduction of BAT in the industrial sector of the Russian Federation within the framework of the federal project "Implementation of the best available technologies".

The recommended document, according to the author's idea, consists of 6 main sections, as well as 3 annexes. The main concept of this standard is to establish clear requirements for the procedure and procedure for conducting public audits of the introduction of BAT in enterprises that have a harmful effect on the environment.

Moreover, as an option, the author recommends using the following title of the proposed document: National Standard of the Russian Federation "Best Available Technologies. Methodological recommendations for conducting a public expert environmental and technological assessment of the introduction of BAT in enterprises".

\section{Characteristics of the individual elements of the proposed document}

In the first Section of the proposed standard, it is planned to describe and give a clear justification for the scope of its application, to list the subjects by which it will be recommended for use. According to the author's idea, the document will be addressed to subjects of public control, legal entities and individual entrepreneurs engaged in economic and (or) other activities at Category I facilities that have a negative impact on the environment, as well as direct experts from BAT involved to conduct a public expert environmental and technological assessment of the introduction of BAT and other interested parties. 
In the second Section ("Normative References"), it is planned to list key interstate standards or classifiers that directly or indirectly affect aspects related to activities in the field of public control of the introduction of BAT in modern enterprises. In this case, links to the following documents will be used:

- State Technical Standard of Russian Federation (GOST R), compatible with ISO 140502009 "Environmental Management. Dictionary";

- GOST R 56828.5-2015 NDT "Methodological recommendations on the procedure for using the information and technical reference on the best available technologies in assessing the environmental impact of designed enterprises";

- GOST R 56828.6-2015 BAT "Methodological recommendations on the procedure for applying the information and technical reference book on the best available technologies in the assessment (examination, competitive selection) of enterprise modernization projects aimed at achieving the requirements of the best available technologies (introduction of BAT)";

- GOST R 113.00.02-2019 BAT "Methodological recommendations for building a structure for evaluating technological processes, equipment, technical methods and methods in terms of meeting the requirements of the best available technologies";

- GOST R 113.00.04-2020 "The best available technologies. Technology Description Format".

Within the framework of the third Section, it is planned to give clear definitions of key terms that will be applied in the proposed standard for implementation, including such conceptual categories as: a) initiator of a public audit; b) information and technical reference; c) integrated environmental permition; d) the best available technology; e) negative impact on the environment; e) emission standards; g) standards for permissible discharges; h) object of public inspection; j) public inspection; k) public expert environmental and technological assessment, etc.

In the fourth Section "General Provisions", according to the author's idea, the following will be listed:

a) the objectives of the federal project "Implementation of the best available technologies", as well as the most proposed federal standard for introduction;

b) the rights of subjects of public control;

c) forms of its implementation (including such as: monitoring, public inspection, examination, public hearings, public discussions);

d) the obligations of legal entities and individual entrepreneurs in the field of confirmation of the implementation of the best available technologies in production, etc.

In the fifth Section ("Organization and conduct of public audits for an expert environmental and technological assessment of the introduction of BAT"), the following will be highlighted: types of public audits (including scheduled and unscheduled); the grounds for their implementation that are indicated; rights and obligations of initiators; the procedure for determining and regulating deadlines; information necessary for inclusion in the programs of relevant checks; rules on access to information on their results, etc.

Within the framework of the Section under development, it is also recommended to limit the time for each individual public inspection to limits that, according to the author's idea and, guided by the principle of reasonable necessity, should not exceed thirty calendar days.

In more detail and in detail the content of public inspections proposed for implementation will be set out in Annex "A" to the recommended standard. Currently, the author of this article is actively working in this direction.

In addition to other information, it is proposed to include in the fifth Section of the standard the requirements for the content of the final act drawn up based on the results of a public audit. In particular, it is recommended to place the following structural elements here: 
a) the grounds for conducting a public audit of the introduction of BAT;

b) a list of documents and other materials studied during a public audit of the introduction of BAT;

c) the results of the environmental and technological assessment of the introduction of BAT at the enterprise;

d) conclusions on the results of a public audit of the introduction of BAT, suggestions and recommendations for eliminating identified violations, etc.

For clarity and convenience of the users of the standard, a sample of the final act is planned to be placed as part of a separate Annex (B).

At the same time, in the sixth Section of the standard ("Expert environmental and technological assessment of the introduction of BAT"), it is proposed to highlight the subject of an expert environmental and technological assessment of the introduction of BAT, which should be understood as: technological processes, equipment, technical methods used in the implementation of economic and (or) other activities at facilities that have a negative impact on the environment, which (in accordance with Decree of the Government of the Russian Federation of September 28, 2015 No. 1029) was assigned Category I when it was registered with the state registration of facilities, providing negative impact on the environment. It should be clarified that, on a voluntary basis, the subject of evaluation can also be technological processes, equipment, technical methods used in carrying out economic and (or) other activities at an object that has a negative impact on the environment, to which Category II is assigned when registration with the state of facilities providing negative impact on the environment.

Also in the sixth Section, it is planned to list the key components of the process of expert environmental and technological assessment of the introduction of BAT, including such as:

1) Evaluation of information about what areas of application of BAT include technological processes, equipment, technical methods and methods used at the public inspection facility;

2) Conducting a comprehensive assessment of the selection of measures for the implementation of the best available technologies at this facility;

3) Analysis of the adequacy of measures for the introduction of technological processes, equipment, technical methods and methods at the enterprise;

4) Evaluation of the feasibility of improving the indicators achieved by the relevant facility to ensure compliance with industry standards for BAT;

5) If necessary, a general assessment of the economic nature of the introduction of BAT.

In addition to other information, it is recommended that the developed standard also include a general list of parameters, criteria and results of an expert environmentaltechnological assessment of BAT implementation. For clarity, the statements formulated in this direction are presented in the framework of Table 1.

Table 1. General list of parameters, criteria and results of expert environmental-technological assessment of BAT implementation

\begin{tabular}{|c|c|c|}
\hline Evaluation Options & Evaluation Objects & Evaluation Results \\
\hline \hline Scope of BAT & List of BAT applications & $\begin{array}{c}\text { Confirmation / Request for } \\
\text { more information }\end{array}$ \\
\hline $\begin{array}{c}\text { Selection of measures for } \\
\text { the implementation of } \\
\text { BAT }\end{array}$ & $\begin{array}{c}\text { Technological processes, equip- } \\
\text { ment, technical methods and } \\
\text { methods }\end{array}$ & $\begin{array}{c}\text { Confirmation / Request for } \\
\text { more information }\end{array}$ \\
\hline $\begin{array}{c}\text { Analysis of the adequacy } \\
\text { of measures for the im- } \\
\text { plementation of BAT }\end{array}$ & BAT industry indicators & $\begin{array}{c}\text { Confirmation / Request for } \\
\text { more information }\end{array}$ \\
\hline
\end{tabular}




\begin{tabular}{|c|c|c|}
\hline Evaluation Options & Evaluation Objects & Evaluation Results \\
\hline \hline $\begin{array}{c}\text { Assessment of the need to } \\
\text { improve technological } \\
\text { parameters of BAT }\end{array}$ & Promising technology & $\begin{array}{c}\text { Confirmation / Request for } \\
\text { more information }\end{array}$ \\
\hline $\begin{array}{c}\text { Assessment of economic } \\
\text { information on the intro- } \\
\text { duction of BAT }\end{array}$ & $\begin{array}{c}\text { Financial reporting justifying the } \\
\text { choice of decisions on the BAT } \\
\text { implementation }\end{array}$ & $\begin{array}{c}\text { Confirmation / Request for } \\
\text { more information }\end{array}$ \\
\hline
\end{tabular}

Thus, Table 1 provides a general list of parameters, criteria and results of an expert environmental and technological assessment of the introduction of BAT, which is recommended to be oriented in the standard proposed by the author.

\section{Forecasts and expectations}

The proposed standard is presented as a comprehensive document aimed at solving a whole range of pressing problems in the field under study. It is expected that its implementation will contribute to enhancing the transparency of financial flows allocated for the implementation of the National Project "Ecology", as well as its separate Federal Project, "Implementation of the Best Available Technologies". A general increase in the effectiveness of environmental policy implemented in our country is also expected.

\section{Conclusion}

Thus, in the framework of this article, the role of public control of the best available technologies in the implementation of priority areas of the country's environmental policy is considered. As was shown during the study, the national Standard recommended for implementation will consist of 6 main Sections and 3 Annexes. The main concept of the proposed document is to establish clear requirements for the procedure for conducting public audits of the introduction of BAT in enterprises that cause a harmful effect to the environment of Category I.

It is substantiated that the introduction of the developed standard as a whole will contribute to the implementation of a qualitative and timely independent assessment of the effectiveness of the introduction of BAT in the industrial sector of Russia, which will increase the overall efficiency of the entire National Project "Ecology", as well as its separate Federal project, "Implementation the best available technology".

\section{References}

1. Federal Law of the Russian Federation of June 28, 2014 No. 172-FZ "On strategic planning in the Russian Federation” (Russian Newspaper Pub., Moscow, 2014)

2. Decree of the Government of the Russian Federation of April 15, 2014 No. 328 "On approval of the state program of the Russian Federation " Development of industry and increasing its competitiveness” (Russian Newspaper Pub., Moscow, 2014)

3. Federal Law of January 10, 2002 No. 7-FZ “On Environmental Protection” (Russian Newspaper Pub., Moscow, 2014)

4. Federal Law of the Russian Federation dated December 31, 2014 No. 488-FZ "On Industrial Policy in the Russian Federation" (Russian Newspaper Pub., Moscow, 2014) 
5. Federal Law of the Russian Federation of November 23, 2009 No. 261-FZ "On energy saving and on improving energy efficiency and on making amendments to certain legislative acts of the Russian Federation" (Russian Newspaper Pub., Moscow, 2014)

6. A.B. Efremenkov, A.A. Khoreshok, S.A. Zhironkin, A.V. Myaskov, IOP Conference Series Earth and Environmental Science, 50(1), 012009 (2017)

7. M. Kovalchuk, O. Naraikin, Security Index, 3-4(118-119), 103-108 (2016)

8. K.N. Trubetskoy, A.V. Myaskov, Y.P. Galchenko, V.A. Eremenko, Gornyi Zhurnal, 5, 613 (2019)

9. A. Myaskov, S. Kostyuk, D. Marinova, E3S Web of Conferences, 105, 02009 (2019)

10. D. Evrard, J. Villot, C. Armiyaou, V. Laforest, R. Gaucher, S. Bouhrizi, Journal of Cleaner Production, 176, 1034-1044 (2018)

11. A. Jamrozik, R. Wisniowski, A. Gonet, Conference proceedings: 19th international multidisciplinary scientific geoconference SGEM 2019, 1099-1108 (2019)

12. E.G. Gasho, I.A. Gasho, Journal of physics, 5, 22-24 (2018) 